\title{
AC 2010-241: PANEL DISCUSSION: HOW CAN ENGINEERING ECONOMY CONCEPTS AND TECHNIQUES BE INCLUDED IN ALL ENGINEERING CURRICULA?
}

\section{Leland Blank, Texas A\&M University}

Leland Blank, $\mathrm{PhD}, \mathrm{PE}$, is Dean Emeritus of Engineering at the American University of Sharjah (AUS), United Arab Emirates, and Professor Emeritus of Industrial and Systems Engineering at Texas A\&M University. While serving at AUS, all undergraduate and graduate programs were accredited by UAE and US agencies, including full ABET accreditation. Lee is currently a Visiting Professor at Texas A\&M University at Qatar in Doha.

He is a Past President and Fellow of the Institute of Industrial Engineers. He has served higher education internationally in the UAE, Qatar, Saudi Arabia, Australia, Hungary, China, Japan, and South Africa.

In addition to his academic appointments, Dr. Blank worked in industry for Southwestern Bell Telephone, GTE Data Services, and San Antonio Public Service.

Lee has authored nine engineering textbooks for McGraw-Hill on the subjects of engineering economy and engineering statistics. His current book is the 7th edition of Engineering Economy (in preparation for 2011 release).

His primary areas of interest are engineering economics, international higher education, and strategic planning. 


\section{Panel Discussion: How Can Engineering Economy Concepts and Techniques Be Included in All Engineering Curricula?}

The inclusion of engineering economics in BS curricula for all engineering disciplines faces two opposing challenges.

Reduced completion time: An imperative to reduce the number of credits hours necessary to complete an undergraduate engineering degree often has cost reduction of delivering higher education as a motivating factor.

Additional coverage: The pressure of accreditation-required inclusion of a foundation level of economic analysis and financial basics in all engineering curricula is increasingly felt. This is in addition to the inclusion of safety, legal, ethical, and environmental aspects that may impact engineering projects.

On one hand, these pressures to do more for less in less time means that formal treatment of engineering economics in a separate course is often considered for removal from an engineering curriculum that currently includes it. On the other hand, the topic of a separate course in engineering economics is not seriously considered for inclusion as curricula are revised.

Only a few engineering discipline curricula include formal training in project costing and economic analysis; usually, industrial, manufacturing, civil, petroleum, and engineering management. Commonly, other curricula, such as, mechanical, chemical, nuclear, and electrical usually include some of the concepts and techniques of engineering economics in a small number of classes or laboratory sessions, with possibly some material in the required senior-level design course. This approach meets the accreditation requirement; however, it does little to adequately prepare graduates to be economically-minded as they enter the engineering workforce.

The purpose of the panel discussion is to develop innovative, plausible approaches to including the most important concepts and topics of engineering economics in all engineering curricula in such a fashion that faculty might accept them as a primary knowledge base, even in the face of these external pressures.

Following a brief stage-setting introduction and potential discussion questions/topics by the moderator, the session will be one of open interface between the audience and panel members, facilitated by a moderator. Panel participants will not make individual formal presentations. Notes on the major points made and conclusions reached will be electronically distributed to the audience members after the session is complete.

Some of the possible topics that the panel and audience members may discuss are:

- What are the minimum engineering economy topics that should be included in all engineering curricula? 
- What might an ABET reviewer expect to see covered in the area of 'economics' when reviewing for accreditation renewal?

- How can technology be used to infuse engineering economics into curricula and courses?

- How can engineering economy topics be integrated into existing courses in any BS-level engineering curriculum?

- When is a separate course in engineering economy justified?

The panel is comprised of individuals with varied backgrounds and different engineering disciplines, who come to the discussion with significantly different views of the need and format of engineering economics in engineering curricula. The panel members include:

Dr. Dave Holger

Dr. John White

Dr. Hector Carrasco
ABET, President 2009-2010

Iowa State University: Associate Provost for Academic Affairs

Dean, Graduate College

Professor, Aerospace Engineering

University of Arkansas: Distinguished Professor, Industrial

Engineering

Chancellor Emeritus

Colorado State University-Pueblo: Dean, College of Education, Engineering, and Professional Studies

Professor, Engineering

Dr. Heather Natchmann University of Arkansas: Associate Professor, Industrial Engineering

Director, Mack-Blackwell Rural Transportation Center

Dr. Lee Blank
Texas A\&M University: Professor Emeritus, Industrial and

Systems Engineering

Visiting Professor, Texas A\&M University at Qatar American University of Sharjah, UAE: Dean Emeritus 